\title{
ARTHROSCOPIC STUDY OF INJURIES IN ARTICULAR FRACTURES OF DISTAL RADIUS EXTREMITY
}

\author{
Marcelo Araf ${ }^{1}$, Rames Mattar Junior ${ }^{2}$
}

\section{ABSTRACT}

Objective: To analyze the incidence of wrist ligament and cartilage associated fractures of the distal radius, through arthroscopy, correlating with AO/ASIF classification. Methods: Thirty patients aged between 20 and 50 years old, with closed fracture from groups $B$ and $C$ according to $A O / A S I F$ classification were selected. All of them were submitted to wrist arthroscopy to address intra-articular injuries and reduction and osteosynthesis of the fracture. Results: A high incidence of intra-articular injuries was noticed, and $76.6 \%$ of them presented injury of the triangular fibrocartilage complex, $36.6 \%$ of the intrinsic scapho- lunate ligament, $6.6 \%$ of the intrinsic triquetrolunate ligament, and $33 \%$ articular cartilage injury larger than three millimeters. Patients with fractures from type $\mathrm{C}$ according to AO/ASIF classification presented a higher incidence of ligament injuries. Conclusion: There is no relationship between the presence of chondral injury and the AO/ASIF classification of the fractures in the cases reported in this study. Level of Evidence III, Non Randomized Controlled Trial.

Keywords: Arthroscopy/classification. Wrist injuries. Ligaments. Cartilage, Articular.

Citation: Araf M, Mattar Junior R. Arthroscopic study of injuries in articular fractures of distal radius extremity. Acta Ortop Bras. [online]. 2014;22(3):144-50. Available from URL: http://www.scielo.br/aob.

\section{INTRODUCTION}

The functional outcome of the treatment of intra-articular distal radius fractures is influenced by the anatomical reduction of the articular surface and extra-articular alignment of the distal part of the radius. Numerous studies have shown that persistent joint deviation after an intra-articular distal radius fracture may predispose to the development of post traumatic osteoarthritis. ${ }^{1}$ Knirk and Jupiter ${ }^{2}$ reported that deviations of two millimeters or more of articular distal radius fragments result in post-traumatic osteoarthritis, whereas other researchers such as Fernandez and Geissler, ${ }^{3}$ consider that one millimeter deviation results in pain and stiffness of the wrist.

According to Geissler, ${ }^{4}$ no method proved to be as effective in the diagnosis of soft tissue injuries or cartilage as arthroscopy. According to the author, these injuries are more common than expected. He believes that arthroscopy has revolutionized orthopedic practice, promoting the technical ability to examine and treat intra-articular abnormalities. The wrist arthroscopy is an already established method of diagnosing and treatment, being first used successfully in Japan in $1970 .{ }^{5}$

Fischer et al. ${ }^{6}$ studied 54 patients with extra-articular distal radius fractures through wrist arthroscopy and found severe li- gament injury in $41 \%$ of patients. Few publications analyze the incidence of lesions of the triangular fibrocartilage complex, intrinsic scapholunate and lunate ligament injury, and intrinsic triquetrolunate ligament associated with fractures of the distal forearm bones. No data regarding correlation of incidence of these lesions with the type or severity of the fracture was found in our midst. The cause of persistent pain and limited mobility of the wrist, after appropriate treatment of distal radius fracture can be due to lack of a more accurate method of diagnosis and treatment of associated injuries. ${ }^{7}$

To Mattar Jr and Rezende, ${ }^{8}$ current wrist arthroscopy is an excellent diagnostic and therapeutic tool. However, according to the authors, the basic principles governing the Orthopaedics and Traumatology should be emphasized, endorsing its indication on careful analysis of clinical history, physical examination and any ancillary tests. This technique allows us to evaluate and treat ligament and chondral injuries, as well as articulate and staging joint pathologies.

Arthroscopy is useful both for diagnosis and treatment of injuries by debridement, ligament rehabilitation, resection of bone and cartilage loose fragments, synovectomy, bone shortening, and also to assist in the reduction of fractures. ${ }^{9}$

All the authors declare that there is no potential conflict of interest referring to this article.

\footnotetext{
1. Hospital Municipal "Dr. Carmino Caricchio", São Paulo, SP, Brazil.

2. Department of Orthopedics and Traumatology, Faculdade de Medicina da Universidade de São Paulo, São Paulo, SP, Brazil. 
This research aimed to study the incidence of ligament and cartilage lesions observed by wrist arthroscopy, associated with intra-articular fractures of the distal radius with deviation. The incidence of ligament injuries and intra-articular cartilaginous wrist were correlated with the type of distal radius fracture (classification), cause of trauma, age and gender.

\section{METHODS}

This study was conducted from July 2005 to April 2006.

\section{Case Series}

The study group consisted of 30 patients with a history of wrist trauma and of unilateral intra-articular closed fracture of the distal radius with surgical treatment indication (types $\mathrm{B}$ and $\mathrm{C}$ of the AO/ASIF classification), of both genders, aged between 20 and 50 years old.

\section{Inclusion criteria}

Patients of both genders aged 20-50 years old, with intra-articular unilateral fractures of the distal radius, classified as $\mathrm{B}$ or $\mathrm{C}(\mathrm{AO} / \mathrm{ASIF})$ that were closed, and who had no underlying disease that would counter indicate the surgery.

The following data were collected and correlated:

a) Identification: name initial, record, gender and age;

b) Type of accident;

c) Time from trauma to the surgical procedure;

d) Classification of the fracture;

e) Surgical technique for treatment of fracture;

f) Arthroscopy findings: presence of chondral lesions larger than three millimeters and presence of ligament injuries (intrinsic scapholunate, semilunar-triquetrolunate intrinsic and triangular fibrocartilage complex).

Patients in the study underwent a medical interview with identification of mechanism of injury, besides clinical and radiusgraphic examination of the wrist in two views (anteroposterior and absolute profile). These patients were admitted with a request for pre-operative tests, clinical assessment and surgical planning. Lesions were classified according to the AO/ASIF classification for fractures of the distal forearm bones.

For wrist arthroscopy, a traction system and a Chinese mesh were used.

A $2.7 \mathrm{~mm}$ and 30 degrees optic was used, with its respective shirt and trochanter, and inspection and procedure apparatus (probe, "grasp" tweezers type and "basket") were used. "Shavers" (motorized instruments) with $3 \mathrm{~mm}$ ferrule "full radius" type for soft tissue debridement, "burr" to bony parts and infusion under pressure were used (gravity or compressor was used to ensure articular distention).

\section{Surgical Procedure}

Patients underwent anesthesia (brachial plexus block or general anesthesia), in supine position and their affected upper limb underwent traction with $5 \mathrm{~kg}$ through the Chinese network. Exsanguination was performed with Esmarch tracks. Then, infusion of saline was done to distend the joint capsule to the portal level, ${ }^{3-4}$ which is located by palpating the radiuscarpal joint between the third and fourth extensor compartments.

After capsular distension, a small incision is made in this site with scalpel blade number 11. A rhombus trocar with its shirt Acta Ortop Bras. 2014;22(3):144-50 was introduced into the portal and, after removing the trocar, the optic is introduced into the shirt. Then a $40 \times 10$ needle is inserted into the $6 \mathrm{U}$ portal (ulnar to the extensor ulnaris carpi) to provide an exit for the saline (out-flow).

We also used the following portals for visualization and instrumentation: 4,5, and 6R (radiuscarpal) and mediocarpais (radial and ulnar). During arthroscopy, all cartilage and ligament injuries associated with fractures were diagnosed, classified and treated.

After arthroscopic inspection, the procedures for reconstruction of the distal radius fracture (osteosynthesis) were started, with the aid of arthroscopy and image intensifier.

The treatment of fractures was done in closed or open way, using internal fixation with Kirschner wires, screws, with and without "T" plate lock. In cases where open reduction of the radial fracture was performed, we used Henry access way, and in patients showing fracture of the base of the styloid process of the ulna with instability of the distal radius ulnar joint we used the method of tension band. After the surgical procedure, the patient's upper limb was immobilized with antebrachiopalmar or axilopalmar plaster splint, depending on the fracture and the method of attachment. Patients remained hospitalized for another two days for antibiotic therapy and clinical observation, and then monitored as outpatients.

Geissler's arthroscopic classification ${ }^{7}$ were used for intrinsic scapholunate ligament injuries and Palmer classification ${ }^{13}$ for triangular fibrocartilage complex injuries.

\section{Statistical Analysis}

All variables were analyzed descriptively. For quantitative variables, this analysis was done by observing the minimum and maximum values and the calculation of means, standard deviations and medians. For qualitative variables, we calculated absolute and relative frequencies.

In order to analyze the equality hypothesis of groups in these variables, we used the nonparametric Mann-Whitney test, since the assumption of normality of the data was rejected.

To test the homogeneity between proportions of the two groups, the Fisher exact test (which is indicated when the expected frequencies are lower than five) was used.

The significance level used for the tests was $5 \%$.

\section{RESULTS}

Thirty patients aged between 20 and 50 years (mean and standard deviation $40.30 \pm 8.14$ years old; median 41 years old) were analyzed. Seventeen of them $(56.7 \%)$ were male. The time from trauma to surgery ranged from two to 21 days (mean and standard deviation $10.17 \pm 4.92$ days; median 10.50 days). Fifteen patients (50\%) showed lesions on the right side.

Twenty-five patients (83.3\%) had ligament injury. The frequency distribution in relation to the type of lesion (classification) and impaired ligament are shown in Table 1.

Considering ligament injuries alone, 23 patients were found with lesions of the triangular fibrocartilage complex (76.7\%), 11 patients with lesions of the intrinsic scapho-semilunate ligament (36.6\%) and two with lesion of the semilunar-triquetrolunate intrinsic injury (6.6\%).

Ten patients (33.3\%) had chondral lesions greater than $3 \mathrm{~mm}$. The five patients without ligament injuries also had no chondral 
lesion. Of the 25 patients with ligament injuries, 15 showed no chondral lesion and 10 did.

AO/ASIF classification criteria are described in Table 2.

In Figure 1, we observe the relative percentages of AO/ASIF classification of the groups in this series.

Study of ligament injury: in this analysis, patients were divided into two groups, with or without ligament injury and compared in terms of the variables measured.

From Table 3, it was found that groups with ligament injuries showed no statistically significant difference regarding age, gender, side and time of evolution.

Table 4 shows that in groups with ligament injury there is a statistically significant difference regarding AO/ASIF classification. The group with ligament injury has higher percentages of cases in classes C1, C2 and C3 than the group without ligament injury. In this analysis, the group of patients was divided into two: with or without chondral lesion and both were compared in terms of the variables measured.

From Table 5, it is observed that groups with chondral lesions did not show statistically significant differences regarding age, gender, side and time of evolution.

From Table 6, it was observed that no statistically significant difference regarding the mechanism of injury in groups with chondral injury.

In Table 7 we can see groups with chondral lesions that do not show statistically significant differences regarding the type of

Table 1. Absolute and relative frequencies of the type of ligament injury in 30 patients studied.

\begin{tabular}{|c|c|c|}
\hline Joint injury & $\mathbf{n}$ & $\%$ \\
\hline ES (G4) & 1 & 3.3 \\
\hline $\mathrm{CFCT}(\mathrm{P} 1 \mathrm{~A}$ e 1B) & 1 & 3.3 \\
\hline $\mathrm{CFCT}(\mathrm{P} 1 \mathrm{~A}$ e 1C) & 1 & 3.3 \\
\hline $\mathrm{CFCT}(\mathrm{P} 1 \mathrm{~B}$ e 1C) & 1 & 3.3 \\
\hline $\mathrm{CFCT}(\mathrm{P} 1 \mathrm{~B})$ & 4 & 13.3 \\
\hline $\mathrm{CFCT}(\mathrm{P} 1 \mathrm{C})$ & 5 & 16.7 \\
\hline CFCT(P1D) & 1 & 3.3 \\
\hline$E S(G 1)$ & 1 & 3.3 \\
\hline $\mathrm{ES}(\mathrm{G} 1) / \mathrm{CFCT}(\mathrm{P} 1 \mathrm{D})$ & 1 & 3.3 \\
\hline $\mathrm{ES}(\mathrm{G} 2) / \mathrm{CFCT}(\mathrm{P} 1 \mathrm{~A})$ & 1 & 3.3 \\
\hline $\mathrm{ES}(\mathrm{G} 2) / \mathrm{CFCT}(\mathrm{P} 1 \mathrm{~B}$ e 1C) & 2 & 6.7 \\
\hline $\mathrm{ES}(\mathrm{G} 2) / \mathrm{CFCT}(\mathrm{P} 1 \mathrm{C})$ & 2 & 6.7 \\
\hline $\mathrm{ES}(\mathrm{G} 2) / \mathrm{SP} / \mathrm{CFCT}(\mathrm{P} 1 \mathrm{~A})$ & 1 & 3.3 \\
\hline $\mathrm{ES}(\mathrm{G} 3)$ / CFCT(P1A e P1C) & 1 & 3.3 \\
\hline $\mathrm{ES}(\mathrm{G} 3) / \mathrm{CFCT}(\mathrm{P} 1 \mathrm{C})$ & 1 & 3.3 \\
\hline $\mathrm{SP} / \mathrm{CFCT}(\mathrm{P} 1 \mathrm{C})$ & 1 & 3.3 \\
\hline No injury & 5 & 16.7 \\
\hline Total & 30 & 100 \\
\hline
\end{tabular}

Table 2. Absolute and relative frequencies of AO/ASIF classification in 30 patients studied.

\begin{tabular}{|c|c|c|c|}
\hline Variable & Category & $\mathbf{n}$ & $\%$ \\
\hline \multirow{14}{*}{ AO/ASIF Classification } & B1.1 & 1 & 3,3 \\
\hline & B2.1 & 2 & 6,7 \\
\hline & B2.2 & 1 & 3,3 \\
\hline & B2.3 & 2 & 6,7 \\
\hline & B3.1 & 1 & 3,3 \\
\hline & B3.2 & 4 & 13,3 \\
\hline & B3.3 & 1 & 3,3 \\
\hline & C1.1 & 3 & 10,0 \\
\hline & C1.2 & 3 & 10,0 \\
\hline & C1.3 & 2 & 6,7 \\
\hline & $\mathrm{C} 2.1$ & 2 & 6,7 \\
\hline & $\mathrm{C} 2.2$ & 1 & 3,3 \\
\hline & $\mathrm{C} 2.3$ & 4 & 13,3 \\
\hline & C3.2 & 3 & 10,0 \\
\hline
\end{tabular}

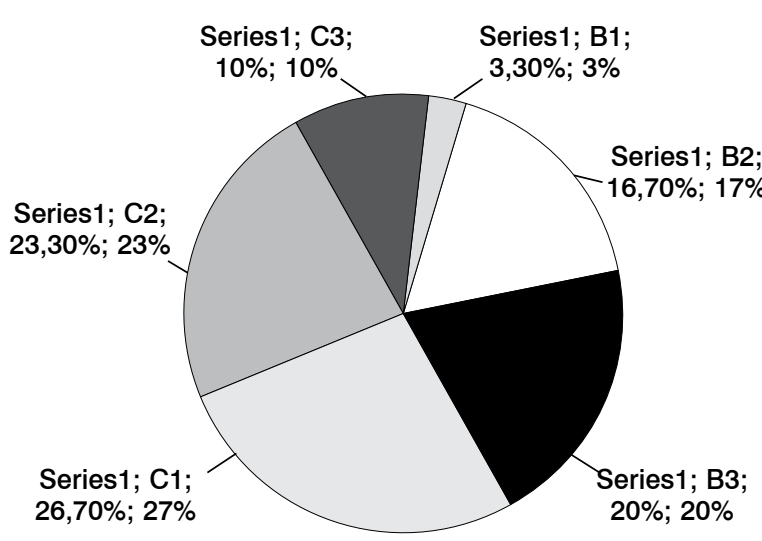

Figure 1. Relative percentages of cases according to AO/ASIF classification

\begin{tabular}{|c|c|c|c|c|}
\hline \multirow{2}{*}{ Variable } & & \multicolumn{2}{|c|}{ Ligament injury } & \multirow{2}{*}{ p } \\
\hline & & No $(n=5)$ & Yes $(n=25)$ & \\
\hline \multirow{3}{*}{ Age (years old) } & Mean + St. Dev. & $41,20 \pm 7,16$ & $40,12 \pm 8,45$ & \multirow{3}{*}{$0,956^{(1)}$} \\
\hline & Median & 42 & 41 & \\
\hline & (Min.; Max.) & $(32 ; 48)$ & $(20 ; 50)$ & \\
\hline Masculine gender & & $3(60 \%)$ & $14(56 \%)$ & $1,000^{(2)}$ \\
\hline Left Side & & $2(40 \%)$ & $13(52 \%)$ & $1,000^{(2)}$ \\
\hline \multirow{3}{*}{ Time of evolution } & Mean + St. Dev. & $10,60 \pm 3,85$ & $10,08 \pm 5,17$ & \multirow{3}{*}{$0,845^{(1)}$} \\
\hline & Median & 10 & 11 & \\
\hline & (Min.; Max.) & $(6 ; 15)$ & $(2 ; 21)$ & \\
\hline
\end{tabular}

(1) Descriptive level of probability of the non-parametric Mann-Whitney test. ${ }^{(2)}$ Descriptive level of probability of the Fisher exact test St. Dev.: Standard Deviation. 
osteosynthesis and according to AO/ASIF classification. In Figure 2, one can observe the absolute percentages of injuries associated with fractures of the distal radius in patients from this series.

Below some of the cases showing distal radius fractures and their associated injuries presented in this study (Figures 3-7) are presented.

Table 4. Absolute and relative frequencies of AO/ASIF classification. according to joint injury.

\begin{tabular}{l|c|c|c|c}
\hline \multirow{2}{*}{ Variable } & & \multicolumn{2}{|c|}{ Ligament injury } & \multirow{2}{*}{$\mathbf{p}^{*}$ (*) } \\
\cline { 2 - 4 } & & No (n=5) & Yes (n= 25) & \\
\hline \multirow{4}{*}{ AO/ASIF Classification } & B1 & $1(20 \%)$ & $0(0 \%)$ & \\
\cline { 2 - 4 } & B2 & $1(20 \%)$ & $4(16 \%)$ & \multirow{2}{*}{0,011} \\
\cline { 2 - 4 } & B3 & $3(60 \%)$ & $3(12 \%)$ & \\
\cline { 2 - 4 } & C1 & $0(0 \%)$ & $8(32 \%)$ & \\
\cline { 2 - 4 } & C2 & $0(0 \%)$ & $7(28 \%)$ & \\
\cline { 2 - 4 } & C3 & $0(0 \%)$ & $3(12 \%)$ & \\
\hline
\end{tabular}

(*) Descriptive level of probability of the Fisher exact test

Table 5. Characterization of patients according to chondral injury.

\begin{tabular}{c|c|c|c|c}
\hline \multirow{2}{*}{ Variable } & & \multicolumn{2}{|c|}{ Chondral injury } & \multirow{2}{*}{ p } \\
\cline { 3 - 4 } & & No ( $\mathbf{n = 2 0 )}$ & Yes (n=10) & \\
\hline \multirow{2}{*}{ Age (years old) } & Mean + St. Dev. & $40,00 \pm 8,63$ & $40,90 \pm 7,46$ & \\
\cline { 2 - 4 } & Median & 41,50 & 40 & \multirow{2}{*}{$0,965^{(1)}$} \\
\cline { 2 - 4 } & (Min.; Max.) & $(20 ; 50)$ & $(29 ; 50)$ & \\
\hline \multirow{2}{*}{ Masculine gender } & & $9(45,0 \%)$ & $8(80,0 \%)$ & \multirow{2}{*}{$0,119^{(2)}$} \\
\hline \multirow{2}{*}{ Left Side } & & $10(50,0 \%)$ & $5(50,0 \%)$ & \multirow{2}{*}{$1,000^{(2)}$} \\
\hline \multirow{2}{*}{ Time of evolution } & Median & 10 & 11,50 & \multirow{2}{*}{$0,930^{(1)}$} \\
\cline { 2 - 4 } & Mean + St. Dev. & $10,35 \pm 4,83$ & $9,80 \pm 5,35$ & \\
\cline { 2 - 4 } & (Min.; Max.) & $(3 ; 21)$ & $(2 ; 16)$ & \\
\hline
\end{tabular}

(1) ) Descriptive level of probability of the non-parametric Mann-Whitney test. (2) Descriptive level of probability of the Fisher exact test. St. Dev.: Standard Deviation.

Table 6. Absolute and relative frequencies of trauma mechanism according to chondral injury.

\begin{tabular}{c|c|c|c}
\hline \multirow{2}{*}{ Cause of trauma } & \multicolumn{2}{|c|}{ Chondral injury } & \multirow{2}{*}{$\mathbf{p}$} \\
\cline { 2 - 3 } & No $(\mathbf{n = 2 0})$ & Yes $(\mathbf{n = 1 0})$ & \\
\hline Traffic accident & $3(15 \%)$ & $3(30 \%)$ & \multirow{2}{*}{0,372} \\
\hline Fall & $17(85 \%)$ & $7(70 \%)$ & \\
\hline
\end{tabular}

$\mathrm{p}=$ Descriptive level of probability of the exact Fisher test.

Acta Ortop Bras. 2014;22(3):144-50
Table 7. Absolute and relative frequencies of AO/ASIF classification according to chondral injury.

\begin{tabular}{c|c|c|c|c}
\hline \multirow{2}{*}{ Variable } & & \multicolumn{2}{|c|}{ Chondral injury } & \multirow{2}{*}{$p$} \\
\cline { 3 - 4 } & & No (n=20) & Yes (n=10) & \\
\hline \multirow{4}{*}{ AO/ASIF Classification } & B1 & $1(5 \%)$ & $0(0 \%)$ & \\
\cline { 2 - 4 } & B2 & $4(20 \%)$ & $1(10 \%)$ & \multirow{2}{*}{0,053} \\
\cline { 2 - 4 } & B3 & $3(60 \%)$ & $0(0 \%)$ & \\
\cline { 2 - 4 } & C1 & $3(60 \%)$ & $2(20 \%)$ & \\
\cline { 2 - 4 } & C2 & $2(10 \%)$ & $5(50 \%)$ & \\
\cline { 2 - 4 } & C3 & $1(5 \%)$ & $2(20 \%)$ & \\
\hline & C3 & & \\
\hline
\end{tabular}

$\mathrm{p}=$ Descriptive level of probability of the Fisher exact test.

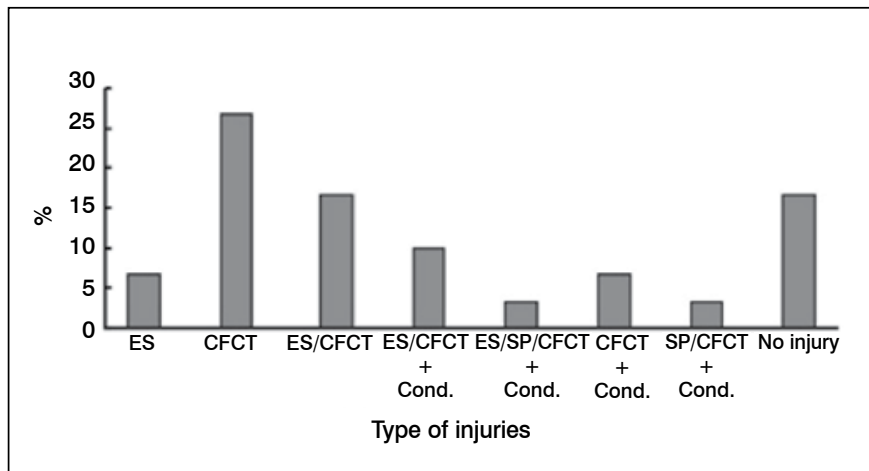

Figure 2. Absolute percentages of associated injuries.
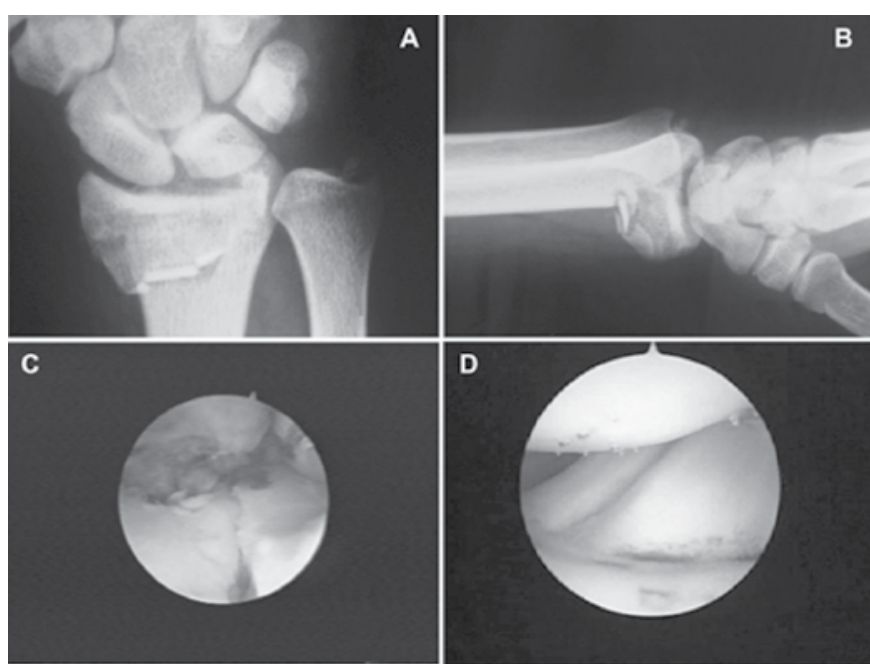

Figure 3. Case $n^{\circ}$ 14. A) X-Ray of wrist in anteroposterior view; B) Profile; C) Arthroscopic view of the fracture; D) Integrity of ulnocarpal joint.

\section{DISCUSSION}

Wrist arthroscopy proved to be an extremely useful tool for the evaluation and treatment of ligament and chondral injuries related to trauma or not. The analyzes in this series and several other studies have shown that this technique allows the assessment associated with fractures of the distal radius injuries, and help their treatment. ${ }^{5}$ 

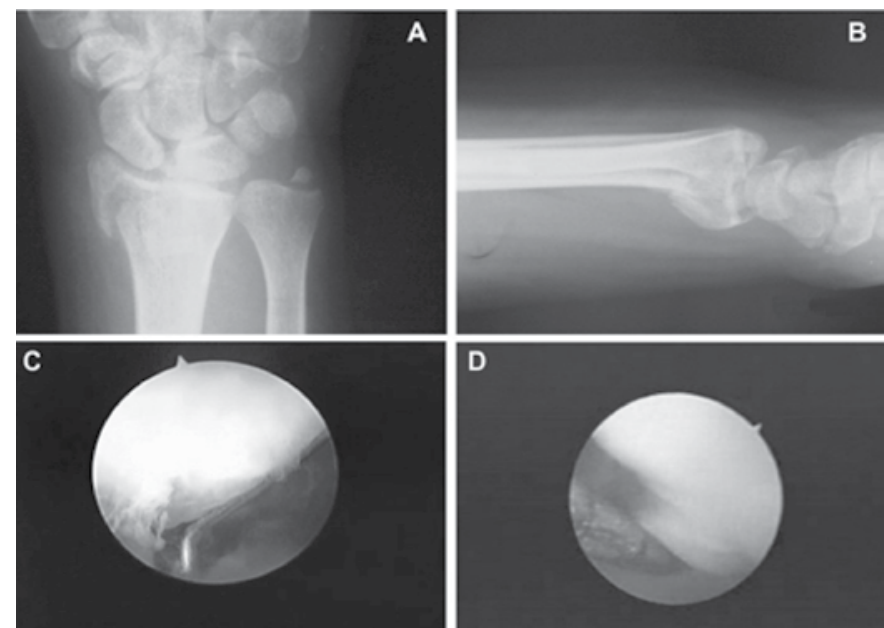

Figure 4. Case $n^{\circ}$ 20. A) X-Ray of wrist in anteroposterior view. B) Profile. C) Palpation of scapholunar intrinsic joint with probe. D) Injury of triangular fibrocartilage complex.
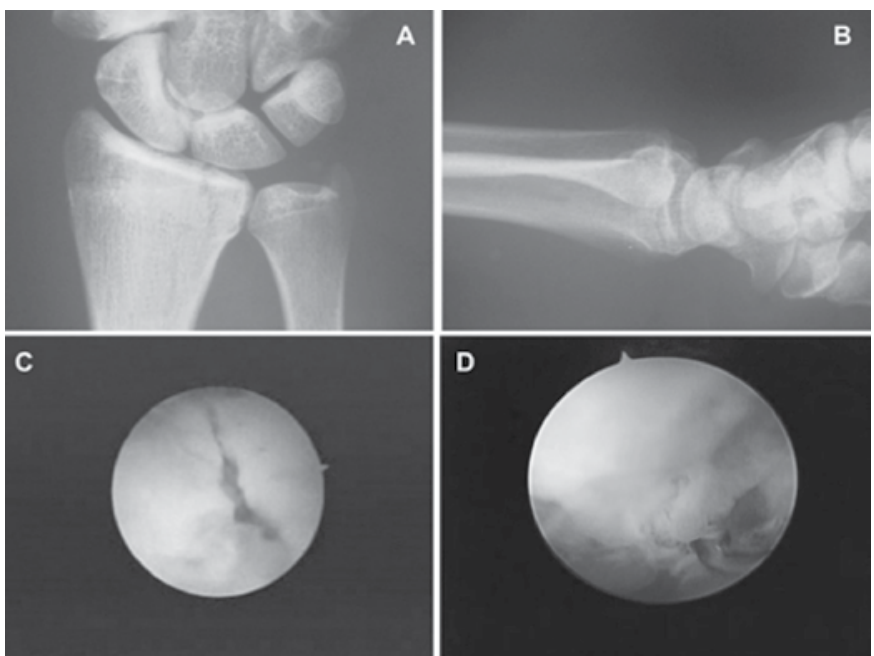

Figure 5. Case $n^{\circ}$ 18. X-Ray of wrist in anteroposterior view. B) Profile. C) View of fracture through athroscopy. D) Scapholunar intrinsic joint injury (Geissler III).
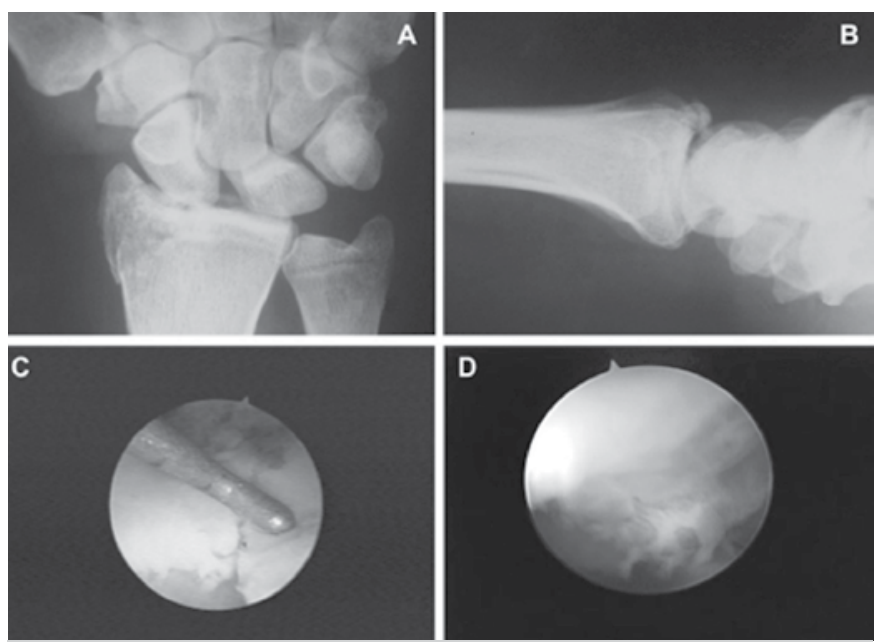

Figure 6. Case $n^{\circ}$ 22. A) X-Ray of wrist in anteroposterior view. B) Profile. C) Reduction of fraction arthroscopically. D) Scapholunar intrinsic joint injury (Geissler IV).
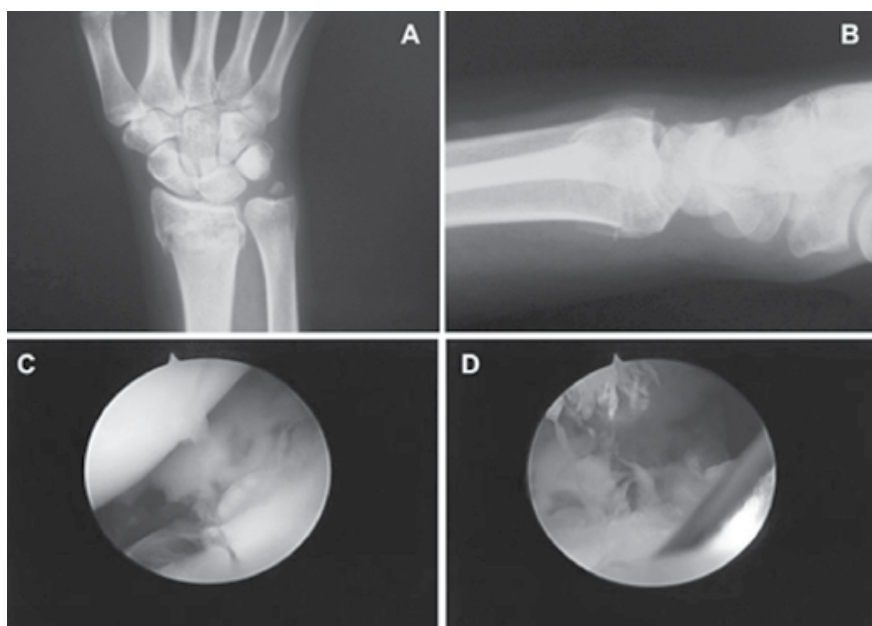

Figure 7. Case $n^{\circ}$ 30. A) X-Ray of wrist in anteroposterior view. B) Profile. C) Chondral injury greater than $3 \mathrm{~mm}$. D) Injury of triangular fibrocartilage complex.

According to Boyer, ${ }^{10}$ the current treatment for fractures of the distal radius is focused on restoring the articular alignment, radius length and volar tilt of the articular surface. The author also points out that early diagnosis and treatment of complications of this injury are very important. This is also our impression. Based on the treatment experience of our patients, it has been prioritized the anatomic reconstruction of the distal radius. Arthroscopy of the wrist can be a very useful technique in some specific cases. The age of the patients chosen for this study was 20 to 50 years old, due to the presence of skeletal maturity and low incidence of osteoporosis. At this age, there are fewer cases of degenerative ligament injuries, such as the triangular fibrocartilage complex. There was no such concern as to age in reviewed articles, showing a wide variation in published case series.

Interestingly, in the study published by Lindau et al. ${ }^{11}$ in 1997, the mean age of patients studied was very similar to that of the present study. Age and gender did not alter the incidence of intra-articular lesions. Probably in the range age and gender studied, there was no interference of these phenomena.

As to the cause of trauma, this sample was divided into injuries caused by traffic accidents (higher energy) and falls (lower energy). No patient experienced a fall from a great height, and thus, their energy is considered a minor trauma intensity. Although we did not observe a correlation between the trauma and the presence of ligament or cartilage lesions associated with fractures, these fractures occurred more frequently in AO/ASIF C-type (complex fractures related to trauma with higher energy). In the present study, in six patients the cause of distal radius fractures was traffic accidents (car, motorcycle, bicycle or run over) and in 24 of them, the cause was fall from standing height or less than one meter high.

Other authors reported causes of trauma, but did not perform correlations with associated injuries. Mehta et al. ${ }^{12}$ analyzed anatomical reduction of these fractures through wrist arthroscopy in 26 patients, 13 fractures being caused by falls and 13 by high-energy trauma.

Geissler et al. ${ }^{5}$ also performed the correlation of soft tissue lesions associated with fractures of the distal radius with the same classification, concluding that most of these injuries oc- 
curred in fractures type $\mathrm{C} 1.2, \mathrm{C} 1.3$ and $\mathrm{C} 3.1$. Other authors have used the AO/ASIF classification in arthroscopic treatment of distal radius fractures, but without correlating it to the presence of associated injuries.

Other authors operated 27 patients with distal radius fracture through wrist arthroscopy, both to evaluate the proper reduction of the fracture, and to ascertaining the presence of associated injuries. In this study, we used Wrist arthroscopy in fractures of the distal extremity of the radius in 30 patients with the aim to analyze and correlate the incidence and correlate ligament and cartilage injuries associated with AO/ASIF classification of these fractures. Although we have performed the treatment of some of the associated injuries, this study aims solely to evaluate the epidemiological aspects of this injury. We found a higher number of ligament injuries related to $\mathrm{C} 1, \mathrm{C} 2$ and $\mathrm{C} 3$ of the AO/ASIF classification and no relationship between this classification and the presence of chondral lesions. Although no classification is ideal, it was considered that there is a tendency to universally use AO/ASIF classification. This was the main reason for choosing this classification, despite having been found papers that identify flaws regarding its reprodutibility. ${ }^{13}$ None of these authors correlated the presence of associated lesions in intra-articular fractures of the distal radius beyond classification, patient's age, cause of trauma and gender. In our study, such correlations were performed. Although any influence of these variables was found in ligaments and cartilage impairment in these fractures, such data were considered very important in the evaluation of these patients.

Richards et al..$^{14}$ used wrist arthroscopy for evaluation of soft tissue injuries associated with extra-or intra-articular fractures of the distal radius in 118 patients. The method was performed in all distal radius fractures requiring surgery and fixation due to failure to obtain or maintain their reduction. In our study, we used only wrist arthroscopy to treat intra-articular injuries. These authors described the presence of lesions of the triangular fibrocartilage complex in 46 patients (39\%).

In this sample, we found lesions of the triangular fibrocartilage complex in $76.7 \%$ of them. This discrepancy may be related to the fact that there have not been included extra-articular injuries of the radius. Another fact was that Richards et al. ${ }^{14}$ did not include patients with avulsion fracture of the ulnar styloid as injury of this complex. The interpretation given here was that the avulsion fracture occurs by traction of ulnocarpal ligaments (semilunar ulna and pyramidal ulna) or the triangular fibrocartilage itself (articular disc). Therefore, it may be related to the triangular fibrocartilage complex injury, its confirmation being performed arthroscopically.

Richards et al. ${ }^{14}$ found that among their patients with large radius shortening due to fracture, the incidence of injury to the triangular fibrocartilage complex was higher. Other authors measured ulnar variance without, however, correlate it to injuries associated with fractures of the distal extremity of the radius. ${ }^{11}$ In this series, we observed a high incidence of injury to the triangular fibrocartilage complex (76.7\%), probably due to the type of fracture studied (displaced fractures and shortening of the radius). Some authors obtained data similar to ours, as Lindau et al. ${ }^{11}$ who reported an injury incidence of $78 \%$ of this complex and also the presence of associated injuries, in a very similar frequency to that of our study.
Azze et al. ${ }^{15}$ conducted an arthroscopic study of wrist joint in 20 cases, which purpose was diagnostic and therapeutic in patients with wrist pain for over four months and without a conclusive diagnosis.

Mattar Jr. et al. ${ }^{16}$ presented their clinical experience with arthroscopy in 37 wrists, underscoring its importance for evaluation and treatment of ligament injuries, fractures and synovitis. It is a fact to consider that some of these cartilaginous lesions, intra-articular loose bodies (osteochondral fragments) can be treated arthroscopically.

Souza et al. ${ }^{17}$ confirmed through macroscopic study in cadaver wrists the importance of arthroscopy in the detection and evaluation of lesions of the triangular fibrocartilage complex.

Rezende et al. ${ }^{18}$ conducted a comparison between imaging studies on the identification of anatomic structures of the wrist, emphasizing the greater accuracy of MRI, with confirmation of lesions identified by wrist arthroscopy.

Peicha et al. ${ }^{19}$ showed in their study the results treatment of lesions of the intrinsic scapholunate ligament associated to intra-articular fractures of distal radius. A temporary percutaneous scapholunate arthrodesis guided by arthroscopy, with good or excellent subjective results in all cases was performed. In our series the incidence of this type of injury was high (36.6\%). Perhaps some cases that progress unsatisfactorily relate with the presence of this undiagnosed injury. On the other hand, less severe lesions in this structure (the Geissler type I) should have a satisfactory evolution without treatment. Other authors used the wrist arthroscopy for treatment of ligament injuries non-associated with distal radius fractures.

Azze et al. ${ }^{15}$ and Mattar Jr. et al. ${ }^{16}$ who treated joint injuries of the scapholunate intrinsic ligament described a new technique of arthroscopic repair of the radial avulsion of the triangular fibrocartilage complex in acute wrist trauma. Mattar et al. ${ }^{20}$ described the arthroscopic treatment of ulnocarpal impingement, concluding that it is an excellent method, providing the return of normal manual activities of patients with congenital positive ulnar variance less than four millimeters. These studies show that it is possible to treat injuries associated with distal radius fractures arthroscopically.

It is important to point out the study of Peicha et al.. ${ }^{19}$ and Geissler, ${ }^{4}$ mentioning the benefits regarding prognosis in lesions of the interosseous ligaments treated early.

The treatment of fractures of the distal radius is still a challenge for Traumatology. Reductions considered appropriate can relate to poor functional results. One possible explanation for these findings is ligament and intra-articular cartilaginous injuries associated with the fractures. Some of these lesions may provide a poor prognosis. Therefore, it is important to know the incidence, characteristics and evolution.

The limited number of publications, the lack of experience and lack of scientific knowledge in this area prompted us to undertake this study. In no published article there was a concomitant correlation between age, gender, mechanism of injury, classification of distal radius fracture and presence of associated intra-articular lesions. Our findings confirm the high incidence of associated injuries, especially those of the triangular fibrocartilage complex and particularly in patients with type $\mathrm{C}$ fractures of the AO/ASIF classification. Other very frequent lesions, such as of articular cartilage, were not affected by the type of fracture. Factors such 
as gender, age and mechanism of injury did not influence the arthroscopic findings. It was considered that such data are of utmost importance in addressing this complex lesion. Likewise, a better understanding of intra-articular lesions can better explain the prognosis of some of these fractures.

\section{CONCLUSIONS}

Most patients with intra-articular fracture types $B$ and $C$ of the AO/ASIF classification have an increased frequency of associated ligament injuries. The most frequent ligament injury was the of the triangular fibrocartilage complex. Patients with type $\mathrm{C}$ fractures of the AO/ASIF classification have a higher incidence of associated ligament injuries. There is no relationship between the presence of chondral lesion greater than three millimeters and the AO/ASIF classification of fractures. There is no relationship between the incidence of ligamentous and chondral injury to the cause of trauma, gender, and age group studied.

\section{REFERENCES}

1. Edwards CC 2nd, Haraszti CJ, McGillivary GR, Gutow AP. Intra-articular distal radius fractures: arthroscopic assessment of radiographically assisted reduction. J Hand Surg Am. 2001;26(6):1036-41.

2. Knirk JL, Jupiter JB. Intra-articular fractures of the distal end of the radius in young adults. J Bone Joint Surg Am. 1986;68(5):647-59.

3. Fernandez DL, Geissler WB. Treatment of displaced articular fractures of the radius. J Hand Surg Am. 1991;16(3):375-84.

4. Geissler WB. Intra-articular distal radius fractures: the role of arthroscopy? Hand Clin. 2005;21(3):407-16.

5. Geissler WB, Freeland AE, Savoie FH, McIntyre LW, Whipple TL. Intracarpa soft-tissue lesions associated with an intra-articular fracture of the distal end of the radius. J Bone Joint Surg Am. 1996;78(3):357-65.

6. Fischer M, Denzler C, Sennwald G. [Carpal ligament lesions associated with fresh distal radius fractures: arthroscopic study of 54 cases]. Swiss Surg. 1996;2(6):269-72

7. Rose S, Frank J, Marzi I. [Diagnostic and therapeutic significance of arthroscopy in distal radius fracture]. Zentralbl Chir. 1999;124(11):984-92.

8. Mattar Júnior R, Rezende MR. Manual de artroscopia do punho. São Paulo: Departamento de Ortopedia e Traumatologia da Faculdade de Medicina da USP; 2001. p.1-3.

9. Shih JT, Lee HM, Hou YT, Tan CM. Arthroscopically-assisted reduction of intra-articular fractures and soft tissue management of distal radius. Hand Surg. 2001;6(2):127-35.

10. Boyer MI. Distal radius fractures: what's in and what's out. Instr Course Lect 2007;56:61-4.

11. Lindau T, Arner M, Hagberg L. Intraarticular lesions in distal fractures of the radius in young adults. A descriptive arthroscopic study in 50 patients. J Hand Surg Br. 1997;22(5):638-43.
12. Mehta JA, Bain GI, Heptinstall RJ. Anatomical reduction of intra-articular fractures of the distal radius. An arthroscopically-assisted approach. J Bone Joint Surg Br. 2000;82(1):79-86

13. Oskam J, Kingma J, Klasen HJ. Interrater reliability for the basic categories of the AO/ASIF's system as a frame of reference for classifying distal radial fractures. Percept Mot Skills. 2001;92(2):589-94

14. Richards RS, Bennett JD, Roth JH, Milne K Jr. Arthroscopic diagnosis of intra-articular soft tissue injuries associated with distal radial fractures. J Hand Surg Am. 1997;22(5):772-6.

15. Azze RJ, Mattar Júnior R, Paula EJL, Starck R, Canedo AC. Estudo artroscópico da articulação do punho: experiência com 20 punhos. Rev Bras Ortop. 1993;28(4):197-200.

16. Mattar Júnior R, Azze RJ, Kimura LK, Paula EJL, Okane SY, Starck R, et al. Artroscopia do punho. Rev Bras Ortop. 1994;29(8):546-50.

17. Souza FI, Zumiotti AV, Mattar Júnior, Rezende MR, Torres LR, Imoto FS. Avaliação artroscópica e macroscópica do complexo da fibrocartilagem triangular do punho. Estudo em cadáveres. Acta Ortop Bras. 2006;14(3)158-60.

18. Rezende MR, Hasegawa OH, Longo CR, Rosemberg LA, Santos DB, Mattar Júnior $\mathrm{R}$, et al. Comparação entre estudos por imagem na identificação das estruturas anatômicas do punho. Rev Bras Ortop. 2005;40(11/12):655-62.

19. Peicha G, Seibert FJ, Fellinger M, Grechenig W, Schippinger G. Lesions of the scapholunate ligaments in acute wrist trauma--arthroscopic diagnosis and minimally invasive treatment. Knee Surg Sports Traumatol Arthrosc. 1997;5(3): 176-83.

20. Mattar Júnior R, Azze RJ, Paula EJL, Rezende MR, Kimura LK, Okane SY. Tratamento por via artroscópica da síndrome do impacto ulno-carpal. Rev Bras Ortop. 2002:37(3)56-66 